\title{
Notch inhibitor mitigates renal ischemia-reperfusion injury in diabetic rats
}

\author{
XIAOKAI DUAN and GUIJUN QIN \\ Department of Endocrinology, The First Affiliated Hospital of Zhengzhou University, Zhengzhou, Henan 450052, P.R. China
}

Received March 15, 2019; Accepted September 26, 2019

DOI: $10.3892 / \mathrm{mmr} .2019 .10857$

\begin{abstract}
Diabetes mellitus can exacerbate renal ischemia-reperfusion $(\mathrm{I} / \mathrm{R})$ injury $(\mathrm{RI} / \mathrm{RI})$ in diabetic rats. Previous studies have shown that Notch signaling is involved in renal disorders. The aim of the present study was to evaluate the protective effect of the Notch inhibitor $\gamma$-secretase $\mathrm{N}$-[N-(3,5-difluorophenacetyl)-L-alanyl]-S-phenylglycine t-butyl ester (DAPT) on RI/RI in a streptozocin (STZ)-induced diabetic rat model. STZ-induced diabetic rats were randomly grouped for different treatments. Cisplatin was used to trigger the Notch signaling pathway and the animals were preconditioned with DAPT to block the signaling pathway. Renal function, oxidative stress and inflammatory factors were examined. DAPT-treated diabetic rats demonstrated mitigated renal injury and function, antioxidative activity was significantly improved and HIF-1a was upregulated. Notch inhibitor DAPT is a potential therapeutic target to improve the outcome of RI/RI in STZ-induced diabetic rats in part via the regulation of anti-oxidation and HIF-1a.
\end{abstract}

\section{Introduction}

Diabetes mellitus (DM) has become a global public health problem increasing each year and the management of diabetic patients requires extensive resources and care (1). It is estimated that diabetes will affect roughly $55 \%$ of old adults in the next two decades and is thus considered a major human health problem (2). Patients with DM exhibit vascular damage, as well as kidney and nerve injury (2,3). DM has also been associated with chronic kidney disease (CKD), which exacerbates into renal ischemia/reperfusion (I/R) injury (RI/RI) (3-5).

Correspondence to: Dr Xiaokai Duan or Professor Guijun Qin, Department of Endocrinology, The First Affiliated Hospital of Zhengzhou University, 56 Tawan West Street, Zhengzhou, Henan 450052, P.R. China

E-mail: 42207682@qq.com

E-mail: gqchen_123@163.com

Key words: diabetes mellitus, Notch, secretase inhibitor, $\mathrm{N}$-[N-(3,5-difluorophenacetyl)-L-alanyl]-S-phenylglycine t-butyl ester, streptozocin model
Physicians and scientists have made efforts in identifying novel therapeutic targets to mitigate the complications of DM.

Signaling pathways have evolved over years in many species (6), for instance during kidney development. Wnt signaling has been shown to function in renal injury $(7,8)$. Notch signaling activation is involved in renal injury and glomerular disease (9). Blocking the Notch signaling pathway has been proven to be effective in rescuing the damage incurred in diabetic conditions (10). One main discovery is that induction of Notch signaling triggers cell death, which further harms tissue activity (11). However, the underlying mechanism of Notch signaling in this diabetic model remains to be elucidated.

To explore the mechanism of Notch signaling in renal function in diabetic models, the present study used a streptozocin (STZ)-induced RI/RI diabetic rat model. $\mathrm{N}$-[N-(3,5-difluorophenacetyl)-L-alanyl]-S-phenylglycine t-butyl ester (DAPT), a $\gamma$-secretase inhibitor of Notch signaling, was administered to animals to examine potential recovery in renal injury. Cisplatin has been reported to induce Notch signaling (12) and thus whether the induction of Notch signaling can be inhibited by DAPT was tested. Its function in renal function and tissue recovery was assessed in a diabetic rat model to provide novel insights on DAPT for potential use in translational clinical studies.

\section{Materials and methods}

Diabetic animal models. A total of 60 Sprague-Dawley male rats (weight: 250-260 g; age: 8 weeks) were obtained from The Shanghai Animal Center. The rats were housed under climate-controlled conditions with a 12-h light/dark cycle and provided with standard food and water ad libitum for 10 days. The rats were randomly dived into two groups; one the control group $(n=10)$ and the remainder the experimental group $(n=50)$, used for the generation of diabetic rat model. The experimental group fasted for $12 \mathrm{~h}$ and then a single dose of STZ (dissolved in citrate buffer, $\mathrm{pH} 4.5,60 \mathrm{mg} / \mathrm{kg}$ body weight) (13) was injected into the abdominal cavity of rats to generate an STZ-induced diabetic rat model. The control group were injected with citrate buffer ( $\mathrm{pH} 4.5$ ). After $72 \mathrm{~h}$, the tail blood was collected to test the levels of serum glucose and those with serum glucose concentrations of $>16.7 \mathrm{mmol} / \mathrm{l}$ were deemed diabetic rats. After 1 week of observation, the diabetic rats were used in subsequent experiments, apart from 6 rats which died due to side effect of 
STZ injection and four rats were not successful for the diabetic rat model. All the experiments complied with the guidance by the animal use and care of The First Affiliated Hospital of Zhengzhou University and the agents were approved by the ethical committee of animal care and use.

Experimental groups. A total of 40 STZ-induced diabetic rats were housed for 16 weeks and randomly assigned into four groups: i) Sham-operated group (sham group), where rats were only treated by separating the bilateral renal arteries and veins and then treated with $10 \%$ dimethyl sulfoxide (DMSO, $1 \mathrm{ml} / \mathrm{kg}$ bw, i.v.) (14-16); ii) RI/RI group (vehicle group), where the rats were treated with ischemia through clamping the bilateral renal arteries and veins for $45 \mathrm{~min}$ followed by $24 \mathrm{~h}$ reperfusion with DMSO (1 ml/kg bw, i.v.); iii) I/R+ DAPT group (DAPT group), where DAPT (dissolved in DMSO, $15 \mathrm{mg} / \mathrm{kg}$ ) was administered as a pretreatment for rats via a single-dose injection into the abdominal cavity at $30 \mathrm{~min}$ prior to the I/R procedure; and iv) I/R+ DAPT + cisplatin group (Cisplatin group), where cisplatin $(15 \mathrm{mg} / \mathrm{kg})$ was intraperitoneally administered to rats at $24 \mathrm{~h}$ prior the $\mathrm{I} / \mathrm{R}$ procedure and DAPT was administered to the animals in the same way as the DAPT group. Animal experiments were performed in accordance with the Guide for the Care and Use of Laboratory Animals of Zhengzhou University. The protocol was approved by the Committee on the Ethics of Animal Experiments of Zhengzhou University.

Tissue collections. Following reperfusion for $24 \mathrm{~h}$, the animals were euthanized using $\mathrm{CO}_{2}$ in a flow rate lower than $30 \%$ chamber vol $/ \mathrm{min}$ and then decapitated to collect blood samples from the abdominal aorta. The collected tissues were centrifuged at $4,000 \times \mathrm{g}$ at $4^{\circ} \mathrm{C}$ for $20 \mathrm{~min}$ to isolate the sera. The entire kidneys were removed and weighed and immediately placed on dry ice or kept at $-80^{\circ} \mathrm{C}$ until further analysis. The kidneys from each group were homogenized in cold normal saline and centrifuged at $4,000 \mathrm{x} \mathrm{g}$ at $4^{\circ} \mathrm{C}$ for $20 \mathrm{~min}$ to obtain the supernatant, which was used for the determination of various parameters.

Renal damage examination. Renal function was evaluated based on the analysis of blood urea nitrogen (BUN) and serum creatinine ( $\mathrm{SCr}$ ). The concentration of BUN and $\mathrm{SCr}$ were analyzed using an automatic biochemistry analyzer (Hitachi 76000; Hitachi High-Technologies Corporation ) according to the manufacturer's protocols.

Analysis of anti-oxidation in renal tissues. Superoxide dismutase (SOD) activity and malondialdehyde (MDA) content in kidney tissues were used as two anti-oxidative markers. SOD activity and MDA were respectively examined at wavelengths of $550 \mathrm{~nm}$ and $532 \mathrm{~nm}$ according to the xanthine oxidase and thiobarbituric acid method (Roche Diagnostics GmbH). The level of lipid peroxides was expressed as $\mathrm{U}$ of $\mathrm{SOD} / \mathrm{mg}$ protein and nmol of MDA/mg protein.

ELISA. Tumor necrosis factor (TNF) $\alpha$, interleukin (IL) 10 and hypoxia-inducible factor (HIF) la levels in kidney tissues were assessed. TNF- $\alpha$ (cat. no. ab4607; Abcam) and IL-10 (cat. no. ab108872; Abcam) levels were measured using ELISA kits according to the manufacturer's protocols. For the HIFla
Table I. Serum level of BUN and SCr in streptozocin-induced diabetic rats.

\begin{tabular}{lcc}
\hline Groups & BUN, mmol/1 & $\mathrm{SCr}, \mu \mathrm{mol} / 1$ \\
\hline Sham & $6.88 \pm 0.43$ & $27.86 \pm 2.53$ \\
Vehicle & $36.50 \pm 3.19^{\mathrm{a}}$ & $118.96 \pm 5.15^{\mathrm{a}}$ \\
DAPT & $20.19 \pm 2.43^{\mathrm{a}, \mathrm{b}}$ & $52.29 \pm 5.14^{\mathrm{a}, \mathrm{b}}$ \\
DAPT + Cisplatin & $25.51 \pm 2.72^{\mathrm{a}, \mathrm{c}}$ & $77.34 \pm 6.40^{\mathrm{a}, \mathrm{c}}$ \\
\hline
\end{tabular}

${ }^{\mathrm{a}} \mathrm{P}<0.05$ vs. sham group; ${ }^{\mathrm{b}} \mathrm{P}<0.01$ vs. vehicle group; ${ }^{\mathrm{c}} \mathrm{P}<0.05$ vs. DAPT group. BUN, blood urea nitrogen; $\mathrm{SCr}$, serum creatinine; DAPT, N-[N-(3,5-difluorophenacetyl)-L-alanyl]-S-phenylglycine t-butyl ester.

evaluation, the quantitative sandwich ELISA method (cat. no. MAN0014317; Thermo Fisher Scientific, Inc.) following the manufacturer's protocols was performed to test the level of HIF1a in diabetic rat model. Briefly, HIF1A standards and samples are captured by a polyclonal HIF1A antibody on the pre-coated plate and detected using a biotinylated monoclonal HIF1A antibody reactive to epitopes other than the capture antibody. The biotinylated detection antibody is then bound to streptavidin-HRP, which catalyzes the conversion of TMB to a colored derivative. Color development is linear for the assay's dynamic range and directly proportional to the amount of HIF1A present in the sample, and the absorbance was measured on a plate reader at $450-550 \mathrm{~nm}$.

Western blotting. Protein levels were examined by western blotting. Briefly, $200 \mu \mathrm{g}$ kidney proteins were extracted with T-PER Tissue Protein Extraction Reagent (cat. no. 78510; Thermo Fisher Scientific, Inc.) and separated 10\% SDS-PAGE. The proteins were transferred to nitrocellulose membranes. After blocking with $5 \%$ bovine serum in TBS buffer containing $0.1 \%$ Tween 20 (TBST) for $1 \mathrm{~h}$, the membranes were incubated at $4{ }^{\circ} \mathrm{C}$ overnight with the following primary antibodies: IL-10 (1:500; cat. no. ab34843; Abcam), TNF- $\alpha$ (1:500; cat. no. ab6671; Abcam) and HIF1A (1:1,000; cat. no. ab243861; Abcam). Following three washes with TBST buffer, the membrane was incubated with the AP-conjugated secondary anti-rabbit antibody at $4^{\circ} \mathrm{C}$ overnight and then further developed using BCIP/NBT (Roche Diagnostics $\mathrm{GmbH}$ ) to visualize the bands. The protein $\beta$-actin was used as a control to confirm equal loading of protein in the gel lanes and to correct western blot signals. Images were captured using a GelView system (Carolina Biological Supply Company).

Reverse transcription-quantitative $(R T-q) P C R$. Kidney tissues (40-60 mg) were frozen in liquid nitrogen and $1 \mathrm{ml}$ of TRIzol ${ }^{\circledR}$ was added (Invitrogen; Thermo Fisher Scientific, Inc.). Total RNA isolation was performed as previously described (17). First-strand cDNA was performed using Superscript II RNase $\mathrm{H}^{-}$Reverse Transcriptase (Invitrogen; Thermo Fisher Scientific, Inc.). qPCR was performed using the SYBR Select Master Mix (cat. no. 4472908; Thermo Fisher Scientific, Inc.). Different primers were used to analyze the levels of target genes: Notch1, mRNA forward primer: 5'-GATGGCCTC 
Sham Vehicle DDAPT DDAPT+Cisplatin

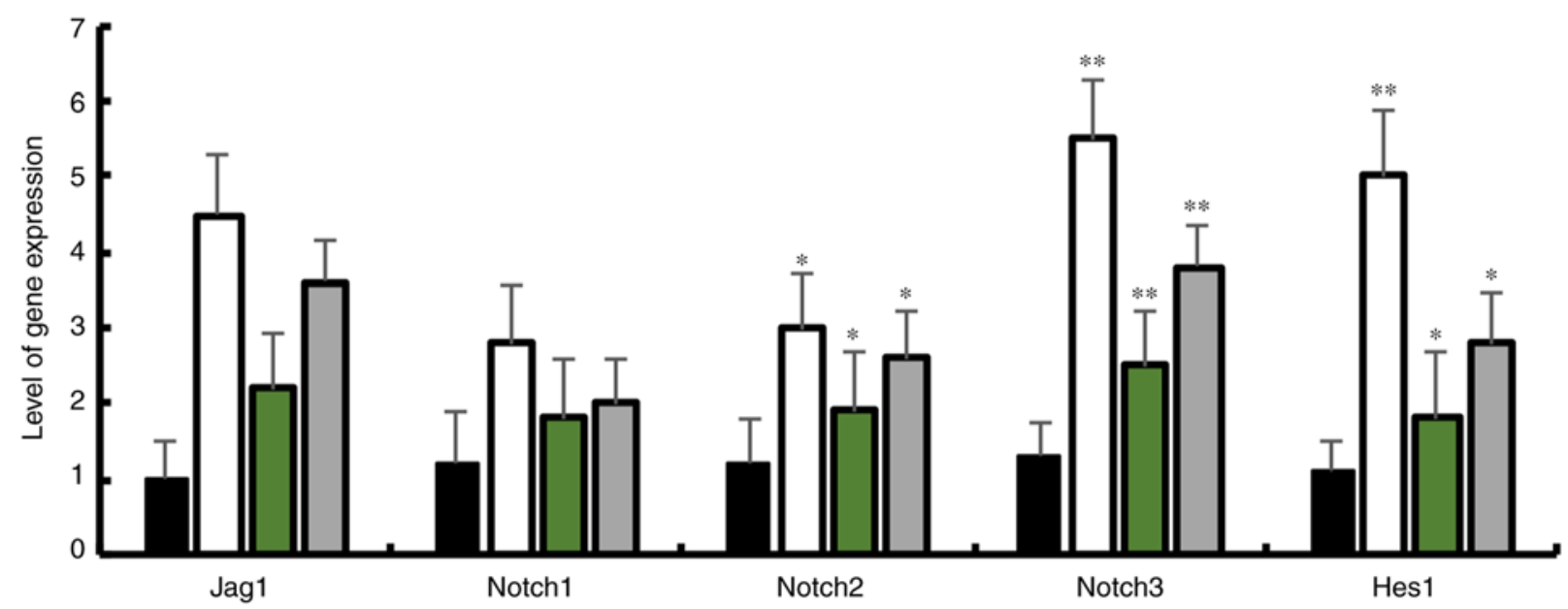

Figure 1. Transcripts of Notch signaling components in streptozocin-induced diabetic rats. Expression levels of Notch1, Notch2, Notch3, Jag1 and Hes1 in diabetic rats were reduced in the DAPT group. mRNA expression levels were normalized against GAPDH. $n=3$. " $\mathrm{P}<0.05$ and ${ }^{* * *} \mathrm{P}<0.01$ compared with the sham group. DAPT, N-[N-(3,5-difluorophenacetyl)-L-alanyl]-S-phenylglycine t-butyl ester; Jag1, Jagged1.

AATGGGTACAAG-3' and reverse primer: 5'-TCGTTGTTG TTGATGTCACAGT-3'; Notch2, forward primer: 5'-GAG AAAAACCGCTGTCAGAATGG-3'; reverse primer: 5'-GGT GGAGTATTGGCAGTCCTC-3'; Notch3, mRNA forward primer: 5'-AGTGCCGATCTGGTACAACTT-3'; reverse primer: 5'-CACTACGGGGTTCTCACACA-3'; Jagged-1, mRNA forward primer: 5'-AACTGGTACCGGTGCGAA-3' and reverse primer: 5'-TGATGCAAGATCTCCCTGAAAC-3' primers; HES-1, forward primer: 5'-CGACACCGGACAAAC CAAA-3', reverse primer: 5'-GAATGTCTGCCTTCTCCA GCTT-3'; and GAPDH, forward primer: 5'-GCAAGAGAG AGGCCCTCAG-3', reverse primer: 5'-TGTGAGGGAGAT GCTCAGTG-3'. The standard conditions for qPCR were: $50^{\circ} \mathrm{C}$ for $10 \mathrm{~min}$ and $95^{\circ} \mathrm{C}$ for $2 \mathrm{~min}$; followed by 50 cycles of denaturation at $95^{\circ} \mathrm{C}$ for $15 \mathrm{sec}$ and $45 \mathrm{sec}$ annealing/elongation at $58^{\circ} \mathrm{C}$ or $60^{\circ} \mathrm{C}$. Relative genes expressions were calculated using the $2^{-\triangle \Delta C q}$ method and the housekeeping gene GAPDH was used as an internal control.

Statistical analysis. Data are presented as the mean \pm standard deviation, and analyzed using SPPS 18.0 (SPSS, Inc.). Comparisons between groups were performed using one-way ANOVA followed by Bonferroni's post hoc test. Unpaired Student t-test was used to analyze the significance between groups. $\mathrm{P}<0.05$ was considered to indicate a statistically significant difference.

\section{Results}

Renal function analysis of STZ-induced diabetic rats. The levels of BUN and $\mathrm{SCr}$ were examined to evaluate changes of renal function. BUN and $\mathrm{SCr}$ levels significantly increased in the RI/RI (vehicle group) compared with the sham group, which was roughly five-fold higher. However, $\mathrm{BUN}$ and $\mathrm{SCr}$ levels in the DAPT and DAPT-cisplatin groups decreased, and those of the DAPT-cisplatin group slightly increased compared with the DAPT group, suggesting that cisplatin-induced Notch signaling was blocked by DAPT (Table I).
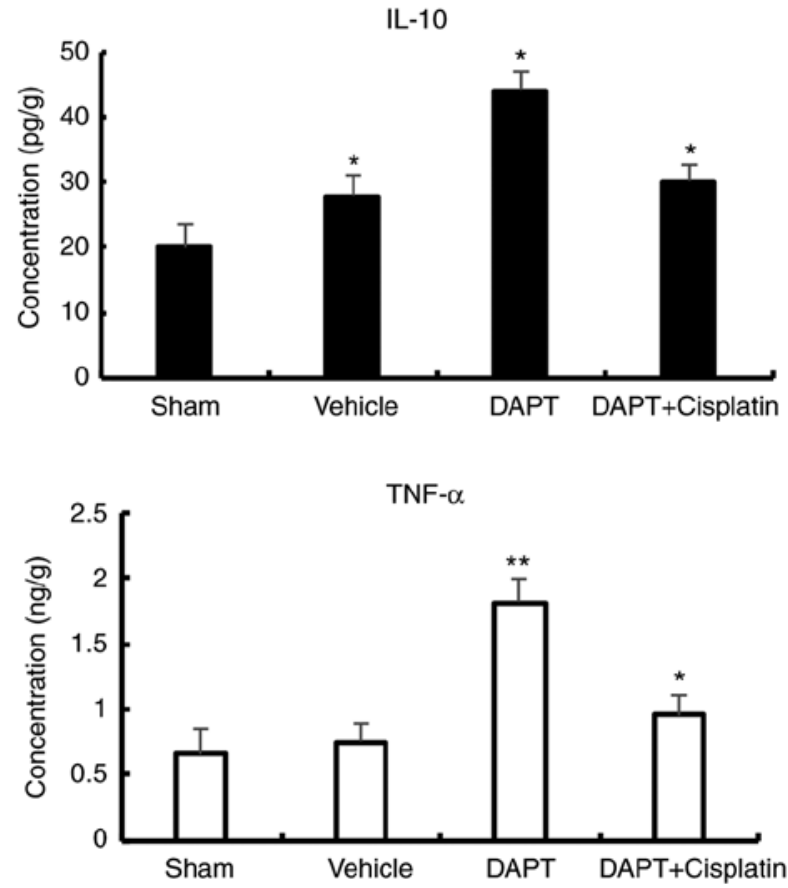

Figure 2. Expression levels of inflammatory factors in streptozocin-induced diabetic rats. After treatment with DAPT, IL-10 and TNF- $\alpha$ expression significantly increased. ${ }^{*} \mathrm{P}<0.05$ and ${ }^{* *} \mathrm{P}<0.01$ compared with the sham group. DAPT, N-[N-(3,5-difluorophenacetyl)-L-alanyl]-S-phenylglycine t-butyl ester; IL, interleukin; TNF, tumor necrosis factor.

Activation of Notch signaling in a diabetic rat model induced by cisplatin. To investigate whether DAPT is sufficient to inhibit the expression of Notch signaling components in STZ-induced diabetic rats, the expression patterns of Jagged1, Notch1, Notch2, Notch3 and Hes1 were analyzed. The data demonstrated that DAPT can significantly reduce the expression of Notch signaling components. DAPT is the inhibitor that was used to block the Notch signaling pathway and injecting DAPT induced the downregulation of Jagged1, Notch 1-3 and Hes1 in the renal 
A

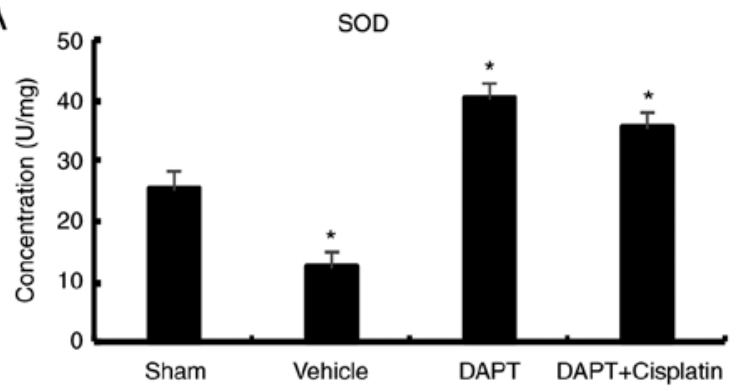

B

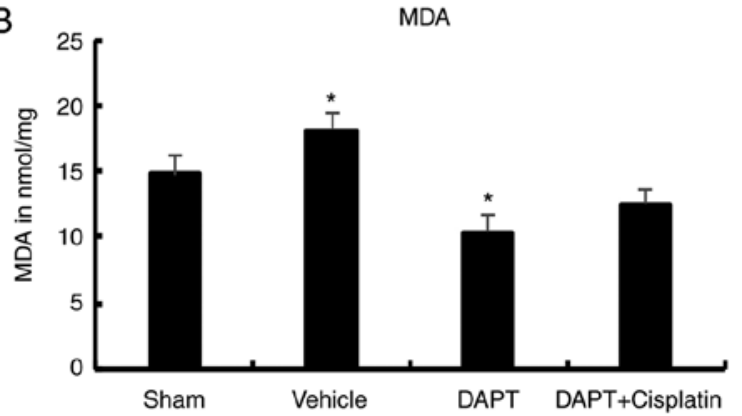

C

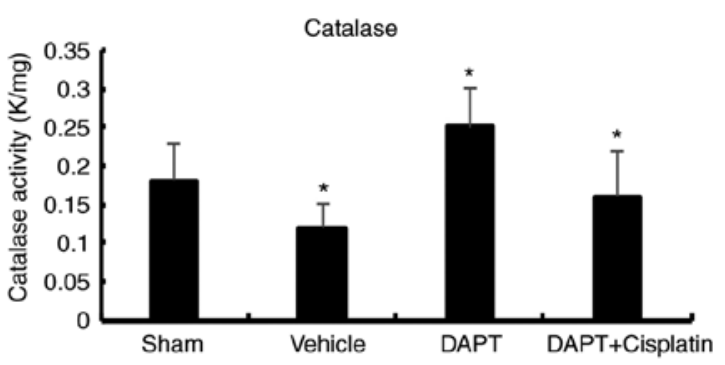

D

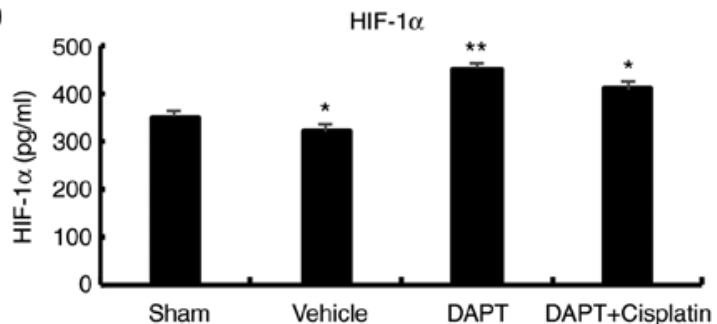

Figure 3. Level of (A) SOD, (B) MDA, (C) catalase and (D) HIF-1a in streptozocin-induced diabetic rats. * $\mathrm{P}<0.05$ and ${ }^{* * *} \mathrm{P}<0.01$ compared with the sham group. SOD, superoxide dismutase; MDA, malondialdehyde; HIF, hypoxia-inducible factor; DAPT, N-[N-(3,5-difluorophenacetyl)-L-alanyl]-S-phenylglycine t-butyl ester.

tissues of STZ-induced diabetic rats, whereas the injection of cisplatin, which is an activator of the Notch signaling pathway, followed by DAPT injection demonstrated similar reductions in the expression of Notch signaling components in diabetic rats (Fig. 1). This data indicates that the upregulation of Notch signaling is reduced in renal tissue after DAPT treatment.

DAPT influences inflammatory factors in SZT-induced diabetic rats. Inflammatory factors have been previously reported to be associated with renal dysfunction in diabetic rats $(18,19)$. The expression of IL-10 (an anti-inflammatory factor) and TNF- $\alpha$ (a pro-inflammatory factor) was examined in the present study. In the vehicle group, the levels of IL-10 $(20.01 \pm 9.26 \mathrm{pg} / \mathrm{g}$ vs. $27.87 \pm 3.17 \mathrm{pg} / \mathrm{g}, \mathrm{P}<0.01)$ and TNF- $\alpha(0.66 \pm 0.11 \mathrm{ng} / \mathrm{g}$ vs. $0.45 \pm 0.07 \mathrm{ng} / \mathrm{g}, \mathrm{P}<0.01)$ were slightly significantly higher than the sham group (Fig. 2). After treatment with DAPT, IL-10 expression significantly increased by roughly two-fold compared with the vehicle rats $(44.15 \pm 9.53 \mathrm{pg} / \mathrm{g}$ vs. $20.01 \pm 9.26 \mathrm{pg} / \mathrm{g})$ and the concentration of TNF- $\alpha$ significantly increased by roughly three-fold $(1.81 \pm 0.09 \mathrm{ng} / \mathrm{g}, \mathrm{P}<0.01)$ compared with the vehicle group. In the DAPT + cisplatin group, IL-10 $(30.13 \pm 3.21 \mathrm{ng} / \mathrm{g})$ and TNF- $\alpha(0.95 \pm 0.12 \mathrm{ng} / \mathrm{g})$ decreased compared with the DAPT group (Fig. 2), suggesting that DAPT may function through the regulation of inflammatory factors to reduce the damage in ischemia-reperfusion injury in diabetic rats.

DAPT attenuates oxidation and HIF levels in STZ-induced diabetic rats. To further explore the effects of DAPT on oxidation, biomarkers for oxidative stress were analyzed. In the vehicle group, SOD activity in the renal tissues significantly decreased compared with the sham group $(12.32 \pm 2.50 \mathrm{U} / \mathrm{mg}$ vs. $25.16 \pm 3.21 \mathrm{U} / \mathrm{mg}, \mathrm{P}<0.01)$. After DAPT treatment, the DAPT group exhibited a significant increase in SOD activity $(40.2 \pm 1.47 \mathrm{U} / \mathrm{mg})$ in the renal tissues compared with the

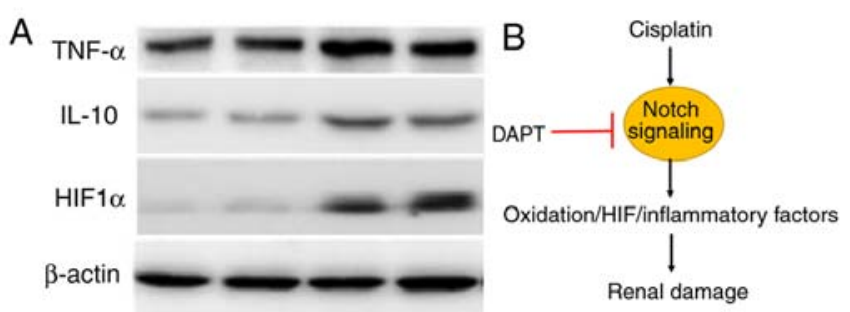

Figure 4. Proposed mechanism of action of DAPT in the cisplatin-induced Notch signaling pathway in STZ-induced diabetic rats. (A) Western blotting demonstrated that DAPT treatment induced higher level of IL-10, TNF- $\alpha$ and HIF1 $\alpha$ expressions. (B) Cisplatin triggers the Notch signaling pathway to increase its levels of oxidation and HIF expression, which induces further damage of the renal tissues. Blockage of Notch using DAPT mitigates renal tissue damage in STZ-induced diabetic rats. DAPT, $\mathrm{N}$-[N-(3,5-difluorophenacetyl)-L-alanyl]-S-phenylglycine t-butyl ester; STZ, streptozocin; IL, interleukin; TNF, tumor necrosis factor; HIF, hypoxia-inducible factor.

vehicle group $(\mathrm{P}<0.01)$. In the DAPT + Cisplatin group, SOD activity significantly decreased compared with the DAPT group $(35.2 \pm 2.45 \mathrm{U} / \mathrm{mg})(\mathrm{P}<0.05)$ but was still higher than the vehicle group (Fig. 3).

Similarly, in the vehicle group, MDA levels increased compared with the sham group $(18.08 \pm 1.33 \mathrm{nmol} / \mathrm{mg}$ vs. $14.78 \pm 1.50 \mathrm{nmol} / \mathrm{mg}, \mathrm{P}<0.05$ ). In the DAPT group, MDA levels significantly decreased $(10.33 \pm 1.47 \mathrm{nmol} / \mathrm{mg})$ in the renal tissues compared with those of the vehicle group $(\mathrm{P}<0.01)$. In the DAPT + Cisplatin group, MDA levels decreased compared with the DAPT group, although this was not statistically significant $(1.21 \pm 0.06 \mathrm{nmol} / \mathrm{mg}, \mathrm{P}>0.05$; Fig. 3).

In the vehicle group, the level of catalase activity decreased compared with the sham group $(0.12 \pm 0.03 \mathrm{~K} / \mathrm{mg}$ vs. $0.18 \pm 0.05 \mathrm{~K} / \mathrm{mg}, \mathrm{P}<0.05$ ). In the DAPT group, catalase levels $(0.25 \pm 0.05 \mathrm{~K} / \mathrm{mg})$ significantly decreased in the renal tissues 
$(\mathrm{P}<0.01)$. In the DAPT + Cisplatin group, the level of catalase activity significantly decreased compared with the DAPT group (0.16 $\pm 0.06, \mathrm{P}<0.05$; Fig. 3).

HIF-1 $\alpha$ expression decreased in the vehicle group compared with the sham group $(320 \pm 12.8 \mathrm{pg} / \mathrm{ml}$ vs. $350 \pm 12.5 \mathrm{pg} / \mathrm{ml}, \mathrm{P}<0.05)$. A significant increase in HIF-1 $\alpha$ expression $(450 \pm 15.3 \mathrm{pg} / \mathrm{ml})$ was observed in the renal tissues after treatment with DAPT $(\mathrm{P}<0.01)$. In the DAPT + Cisplatin group, HIF-1 $\alpha$ expression levels significantly decreased compared with the DAPT group $(410 \pm 14.8 \mathrm{pg} / \mathrm{ml}$, $\mathrm{P}<0.05$; Fig. 3).

Western blotting confirms the function of DAPT in diabetic rats. Western blotting using kidney tissue confirmed TNF- $\alpha$ level in renal tissues in different groups, but the IL-10 levels between DAPT and DAPT + Cisplatin group do not demonstrate a significant difference. Based on the data, DAPT is sufficient to induce the level in ischemia-reperfusion injury in diabetic rats (Fig. 4A). HIF-1 $\alpha$ was significantly expressed in the DAPT groups (Fig. 4A). Overall, our data indicated that DAPT is a suitable factor in reducing renal damage in ischemia-reperfusion injury in STZ-induced diabetic rats via the inhibition of Notch signaling (Fig. 4B).

\section{Discussion}

$\mathrm{DM}$ is a serious challenge to human health and often leads to $\mathrm{CKD}$, exacerbating RI/RI (20). Finding a suitable target to rescue potential renal injury in diabetes animal models is thus imperative. To date, several molecules have been investigated for their effects in mitigating renal injury in different models. The Wnt signaling pathway has been shown to be an ideal target for rescuing renal function in diabetic rat models (21). The inhibitor GSK-3 $\beta$ has been tested for its effects in ischemic diseases and TDZD-8 has been shown to reduce I/R injury by inhibiting inflammation and cell apoptosis (22-24). Notch signaling is an evolutionarily conserved signaling system in cell-cell communications that can regulate cell fate during development. Notch signaling serves a critical role in nephron formation and segmentation and has been reported to be involved in kidney disease. In mouse models, Notch signaling in adult mice has been shown to be pathogenic, leading to defective differentiation of podocytes, cell apoptosis and ultimately renal failure. Blocking the Notch signaling pathway using $\gamma$-secretase inhibitors has been shown to reduce the levels of Notch signaling components in nephrons and podocytes (25). The present study provided further evidence that blocking Notch signaling can rescue the renal defects in STZ-induced diabetic rats, indicating that this may potentially be utilized as a therapeutic approach. However, whether the combination of signaling pathways such as Wnt and Notch can produce more promising therapeutic effects, as well as how these signaling pathways coordinate the regulation of renal function in diabetic models, remains unclear.

Several previous studies have used DAPT to modulate the Notch signaling pathway in diabetic models $(11,25-27)$. DAPT treatment has been shown to enhance neovascularization and reperfusion in diabetic mice (28). DAPT has also been shown to be effective in the treatment of diabetic neuropathic pain (29).
Renal damage is alleviated after DAPT injection (30). Further evidence has indicated that the Jagged1/Notch signaling pathway serves a critical role in TGF- $\beta 2$-induced EMT in human RPE cells (31). The Notch pathway may precipitate diabetic nephropathy via TGF- $\beta$ activation (32) and the Notch1/Hes1-Pten/Akt signaling pathway is involved in a diabetic myocardium (33). Notch signaling has been shown to serve a protective role in RI/RI-associated inflammation and apoptosis (34). The present study demonstrated that DAPT treatment can increase the levels of inflammatory factors as well as anti-oxidative activities and HIF-1a expression, which in turn reduce renal ischemia-reperfusion injury in STZ-induced diabetic rats, thus providing novel insights into the protective role of DAPT in renal function in diabetic models. Although our data demonstrated promising application of DAPT in the recovery of renal damage in I/R injury in STZ-induced diabetic rats, we should be cautious of the potential side effect of Notch inhibition as this intercellular signaling serves myriad roles during development and physiology in vertebrates.

DAPT is a suitable therapeutic target to mitigate mitigates $\mathrm{RI} / \mathrm{RI}$ in STZ-induced diabetic rats. The role of DAPT in renal function may in part work through the regulation on oxidative stress, inflammatory activity and the HIF-1a.

\section{Acknowledgements}

Not applicable.

\section{Funding}

The present study was supported by research grants to Professor Xiaokai Duan from The Medicine Technologies R\&D Program of Henan Province (grant no. 2018020733), The Medicine Education Research Program of Henan Province (grant no. Wjlx 2018291) and support from The Health Commission of Henan Province.

\section{Availability of data and materials}

All data generated or analyzed during the present study are included in this published article.

\section{Authors' contributions}

XD and GQ designed the experiments, performed the data analysis and wrote the manuscript.

\section{Ethics approval and consent to participate}

All the experiments complied with the guidance by the animal use and care of The First Affiliated Hospital of Zhengzhou University and the agents were approved by the Ethical Committee of Animal Care and Use. The protocol was approved by the Committee on the Ethics of Animal Experiments of Zhengzhou University.

\section{Patient consent for publication}

Not applicable. 


\section{Competing interests}

The authors declare that they have no competing interests.

\section{References}

1. Olokoba AB, Obateru OA and Olokoba LB: Type 2 diabetes mellitus: A review of current trends. Oman Med J 27: 269-273, 2012.

2. Caspersen CJ, Thomas GD, Boseman LA, Beckles GL and Albright AL: Aging, diabetes, and the public health system in the United States. Am J Public Health 102: 1482-1497, 2012.

3. O'Gara PT, Kushner FG, Ascheim DD, Casey DE Jr, Chung MK, de Lemos JA, Ettinger SM, Fang JC, Fesmire FM, Franklin BA, et al: 2013 ACCF/AHA guideline for the management of ST-elevation myocardial infarction: A report of the American college of cardiology foundation/American heart association task force on practice guidelines. Circulation 127 e362-e425, 2013.

4. Tong F, Luo L and Liu DJ: Effect of intervention in mast cell function before reperfusion on renal ischemia-reperfusion injury in rats. Kidney Blood Press Res 41: 335-344, 2016.

5. Feng W, Tang R, Ye X, Xue C and Liao Y: Identification of genes and pathways associated with kidney ischemia-reperfusion injury by bioinformatics analyses. Kidney Blood Press Res 41 : 48-54, 2016.

6. Wu T, Chen G, Tian F and Liu HX: Contribution of cranial neural crest cells to mouse skull development. Int J Dev Biol 61: 495-503, 2017.

7. Shen X, Hu B, Xu G, Chen F, Ma R, Zhang N, Liu J, Ma X, Zhu J, Wu Y and Shen R: Activation of Nrf2/HO-1 pathway by glycogen synthase kinase-3 $\beta$ inhibition attenuates renal ischemia/reperfusion injury in diabetic rats. Kidney Blood Press Res 42: 369-378, 2017.

8. Hu B, Wu Y, Liu J, Shen X, Tong F, Xu G and Shen R: GSK-3beta inhibitor induces expression of Nrf2/TrxR2 signaling pathway to protect against renal ischemia/reperfusion injury in diabetic rats. Kidney Blood Press Res 41: 937-946, 2016.

9. Zhang J, Li B, Zheng Z, Kang T, Zeng M, Liu Y and Xia B: Protective effects of Notch1 signaling activation against high glucose-induced myocardial cell injury: Analysis of its mechanisms of action. Int J Mol Med 36: 897-903, 2015.

10. Koshizaka M, Takemoto M, Sato S, Tokuyama H, Fujimoto M, Okabe E, Ishibashi R, Ishikawa T, Tsurutani Y, Onishi S, et al: An angiotensin II type 1 receptor blocker prevents renal injury via inhibition of the Notch pathway in Ins2 Akita diabetic mice. Exp Diabetes Res 2012: 159874, 2012.

11. Bonegio R and Susztak K: Notch signaling in diabetic nephropathy. Exp Cell Res 318: 986-992, 2012

12. Soni H, Matthews AT, Pallikkuth S, Gangaraju R and Adebiyi A $\gamma$-secretase inhibitor DAPT mitigates cisplatin-induced acute kidney injury by suppressing Notch1 signaling. J Cell Mol Med 23: 260-270, 2019.

13. Ramos-Lobo AM, Buonfiglio DC and Cipolla-Neto J: Streptozotocin-induced diabetes disrupts the body temperature daily rhythm in rats. Diabetol Metab Syndr 7: 39, 2015.

14. Njomen GB, Kamgang R, Oyono JL and Njikam N: Antioxidant potential of the methanol-methylene chloride extract of Terminalia glaucescens leaves on mice liver in streptozotocin-induced stress. Indian J Pharmacol 40: 266-270, 2008.

15. Mus LM, Denecker G, Speleman F and Roman BI: Vehicle development, pharmacokinetics and toxicity of the anti-invasive agent 4-fluoro-3',4',5'-trimethoxychalcone in rodents. PLoS One 13 e0192548, 2018.

16. Pearsall EA, Cheng R, Matsuzaki S, Zhou K, Ding L, Ahn B, Kinter M, Humphries KM, Quiambao AB, Farjo RA and Ma JX: Neuroprotective effects of PPAR $\alpha$ in retinopathy of type 1 diabetes. PLoS One 14: e0208399, 2019.

17. Hu B, Wu T, Zhao Y, Xu G, Shen R and Chen G: Physiological signatures of dual embryonic origins in mouse skull vault. Cell Physiol Biochem 43: 2525-2534, 2017.
18. Furuya F, Ishii T and Kitamura K: Chronic inflammation and progression of diabetic kidney disease. Contrib Nephrol 198: 33-39, 2019.

19. Garcia-Garcia PM, Getino-Melián MA, Dominguez-Pimentel V and Navarro-González JF: Inflammation in diabetic kidney disease. World J Diabetes 5: 431-443, 2014.

20. Kazancioğlu R: Risk factors for chronic kidney disease: An update. Kidney Int Suppl (2011) 3: 368-371, 2013.

21. Liu W, Liang X and Yang D: The effects of Chinese medicine on activation of Wnt/ $\beta$-catenin signal pathway under high glucose condition. Evid Based Complement Alternat Med 2015: 295135, 2015.

22. Cuzzocrea $S$, Mazzon $E$, Esposito $E$, Muià $C$, Abdelrahman $M$, Di Paola R, Crisafulli C, Bramanti P and Thiemermann C: Glycogen synthase kinase-3beta inhibition attenuates the development of ischaemia/reperfusion injury of the gut. Intensive Care Med 33: 880-893, 2007.

23. Collino M,Thiemermann C,MastrocolaR, Gallicchio M,BenettiE, Miglio G, Castiglia S, Danni O, Murch O, Dianzani C, et al: Treatment with the glycogen synthase kinase-3beta inhibitor, TDZD-8, affects transient cerebral ischemia/reperfusion injury in the rat hippocampus. Shock 30: 299-307, 2008.

24. Gui B, Hua F, Chen J, Xu Z, Sun H and Qian Y: Protective effects of pretreatment with oleanolic acid in rats in the acute phase of hepatic ischemia-reperfusion injury: Role of the PI3K/Akt pathway. Mediators Inflamm 2014: 451826, 2014

25. Niranjan T, Murea M and Susztak K: The pathogenic role of Notch activation in podocytes. Nephron Exp Nephrol 111: e73-e79, 2009.

26. Lin CL, Wang FS, Hsu YC, Chen CN, Tseng MJ, Saleem MA, Chang PJ and Wang JY: Modulation of notch-1 signaling alleviates vascular endothelial growth factor-mediated diabetic nephropathy. Diabetes 59: 1915-1925, 2010.

27. Marquez-Exposito L, Cantero-Navarro E, Lavoz C, Fierro-Fernández M, Poveda J, Rayego-Mateos S, Rodrigues-Diez RR, Morgado-Pascual JL, Orejudo M, Mezzano S and Ruiz-Ortega M: Could Notch signaling pathway be a potential therapeutic option in renal diseases? Nefrologia 38: 466-475, 2018 (In English, Spanish)

28. Cao L, Arany PR, Kim J, Rivera-Feliciano J, Wang YS, He Z, Rask-Madsen C, King GL and Mooney DJ: Modulating Notch signaling to enhance neovascularization and reperfusion in diabetic mice. Biomaterials 31: 9048-9056, 2010.

29. Yang C, Gao J, Wu B, Yan N, Li H, Ren Y, Kan Y, Liang J, Jiao Y and $\mathrm{Yu}$ Y: Minocycline attenuates the development of diabetic neuropathy by inhibiting spinal cord Notch signaling in rat. Biomed Pharmacother 94: 380-385, 2017.

30. He Y, Zhang M, Wu Y, Jiang H, Fu H, Cai Y, Xu Z, Liu C, Chen B and Yang T: Aberrant activation of Notch-1 signaling inhibits podocyte restoration after islet transplantation in a rat model of diabetic nephropathy. Cell Death Dis 9: 950, 2018.

31. Chen X, Xiao W, Liu X, Zeng M, Luo L, Wu M, Ye S and Liu Y: Blockade of Jagged/Notch pathway abrogates transforming growth factor $\beta 2$-induced epithelial-mesenchymal transition in human retinal pigment epithelium cells. Curr Mol Med 14: 523-534, 2014.

32. Liu L, Gao C, Chen G, Li X, Li J, Wan Q and Xu Y: Notch signaling molecules activate TGF- $\beta$ in rat mesangial cells under high glucose conditions. J Diabetes Res 2013: 979702, 2013.

33. Yu L, Li Z, Dong X, Xue X, Liu Y, Xu S, Zhang J, Han J, Yang $\mathrm{Y}$ and Wang $\mathrm{H}$ : Polydatin protects diabetic heart against ischemia-reperfusion injury via Notch1/Hes1-mediated activation of Pten/Akt signaling. Oxid Med Cell Longev 2018: 2750695, 2018.

34. Huang R, Zhou Q, Veeraragoo P, Yu H and Xiao Z: Notch2/Hespathway plays an important role in renal ischemia and reperfusion injury-associated inflammation and apoptosis and the $\gamma$-secretase inhibitor DAPT has a nephroprotective effect. Ren Fail 33: 207-216, 2011.

This work is licensed under a Creative Commons Attribution-NonCommercial-NoDerivatives 4.0 International (CC BY-NC-ND 4.0) License. 